\section{Pseudohypoxaemia in a patient with acute leukaemia}

\author{
Suchai Charoenratanakul,
} Kittipong Loasuthi

\begin{abstract}
Patients with acute leukaemia may have spuriously low arterial oxygen tensions $\left(\mathrm{PaO}_{2}\right)$. The markedly increased numbers of white blood cells in these patients rapidly consume dissolved plasma oxygen resulting in dramatically decreased $\mathrm{PaO}_{2}$ and calculated oxygen saturations. The case history is reported of a patient with a white blood count of $191000 / \mathrm{mm}^{3}$ in whom multiple arterial blood gas measurements documented hypoxaemia out of proportion to the clinical picture. Pulse oximetry was used to confirm higher haemoglobin oxygen saturations and to establish the spuriously low plasma oxygen tensions in this patient.

(Thorax 1997;52:394-395)
\end{abstract}

Keywords: pseudohypoxaemia, leucocyte larceny, acute leukaemia.

Patients with leukaemia and extremely high white blood counts may have a spuriously low arterial oxygen tension $\left(\mathrm{PaO}_{2}\right)$ because the white blood cells metabolise plasma oxygen in arterial blood gas samples resulting in a spuriously low oxygen tension. ${ }^{1}$ The details of this effect and its importance in the clinical evaluation of the leukaemic patient have been previously described. ${ }^{2}$ We present a case of acute leukaemia with pseudohypoxaemia confirmed in the medical ward by pulse oximetry.

\section{Case report}

A 34 year old woman diagnosed as having acute lymphoblastic leukaemia (ALL) 10 months previously was admitted to hospital with progressive breathlessness. She had noticed a sore throat, cough with mucoid sputum, and fatigue for 10 days prior to admission.

On examination she was not cyanosed but appeared pale and unwell. Her temperature was $38^{\circ} \mathrm{C}$, pulse rate was $90 / \mathrm{min}$, respiratory rate $36 / \mathrm{min}$, and the blood pressure was $110 /$ $70 \mathrm{~mm} \mathrm{Hg}$. The jugular venous pressure was not raised and the heart sounds were normal. Auscultation of the lungs revealed normal breath sounds and the chest radiograph was normal. The complete blood count showed a haemoglobin of $6.9 \mathrm{~g} / \mathrm{dl}$, a haematocrit of $22 \%$, and a white blood count of $191000 / \mathrm{mm}^{3}$ with $77 \%$ lymphoblasts, $10 \%$ neutrophils, $9 \%$ metamyelocytes, $2 \%$ eosinophils, and $2 \%$ band forms. Sputum smears were negative for bacterial organisms and acid fast bacilli.
Table 1 Arterial blood gas tensions

\begin{tabular}{lllll}
\hline & \multicolumn{2}{l}{ In vitro } & \multirow{2}{*}{ In vivo } \\
\cline { 2 - 4 } & $\begin{array}{l}\text { 1st } \\
\text { specimen }\end{array}$ & $\begin{array}{l}\text { 2nd } \\
\text { specimen }\end{array}$ & $\begin{array}{l}\text { 3rd } \\
\text { specimen }\end{array}$ & \\
\hline $\mathrm{PaO}_{2}(\mathrm{kPa})$ & 4.4 & 6.3 & 26.3 & \\
$\mathrm{PaCO}_{2}(\mathrm{kPa})$ & 7.0 & 4.3 & 3.3 & \multirow{2}{*}{94} \\
$\mathrm{SaO}_{2}(\%)$ & 78.7 & 79.8 & 100 & \\
$\mathrm{pH}$ & 7.44 & 7.35 & 7.42 & \\
\hline $\mathrm{PaO}_{2}, \mathrm{PaCO}_{2}=$ & arterial & oxygen and carbon dioxide tensions;
\end{tabular}

$\mathrm{SaO}_{2}=$ arterial oxygen saturation.

She was diagnosed as having bronchitis and was given intravenous cefuroxime and gentamicin with improvement. However, on the second day she complained of an irritating dry cough and dyspnoea. Physical examination of the respiratory and cardiovascular systems remained unchanged and she was not cyanosed. The chest radiograph remained normal. An arterial blood gas sample gave tensions of $\mathrm{PO}_{2}$ $4.4 \mathrm{kPa}, \mathrm{pH} 7.44 . \mathrm{PCO}_{2} 7.0 \mathrm{kPa}, \mathrm{HCO}_{3} 23.5$ with calculated oxygen saturation of $78.7 \%$. Because the arterial blood gas tension showed severe hypoxaemia and the patient was dyspnoeic, she was intubated and placed on a mechanical ventilator. Pseudohypoxaemia was suspected. She was weaned off the respirator and extubated on the same day. Repeat arterial blood gas analysis while she was breathing oxygen via a mask at $10 \mathrm{l} / \mathrm{min}$ revealed $\mathrm{Po}_{2} 6.3$ $\mathrm{kPa}, \mathrm{pH} 7.35, \mathrm{PCO}_{2} 4.3 \mathrm{kPa}, \mathrm{HCO}_{3} 19.7$ with calculated oxygen saturation $79.8 \%$. The patient's clinical status was good and she was comfortable. At this point a pulse oximetry determination (Omeda Biox 3700, Boulder, Colorado, USA) registered haemoglobin oxygen saturation of $94 \%$. A third arterial blood gas specimen, which was immediately iced and analysed, revealed a $\mathrm{Po}_{2}$ of $26.3 \mathrm{kPa}, \mathrm{pH} 7.42$, $\mathrm{PCO}_{2} 3.3 \mathrm{kPa}, \mathrm{HCO}_{3} 17.0$ and calculated oxygen saturation $100 \%$ (table 1 ).

The patient made a good recovery from her upper respiratory tract infection and was discharged from hospital.

\section{Discussion}

The term "leucocyte larceny" was introduced by Fox et al in 1979 to describe the phenomenon of a falsely low plasma oxygen measurement in leukaemia with spurious lowering of the mixed venous $\mathrm{Po}_{2}$ due to oxygen consumption by leucocytes. ${ }^{1}$

Leucocytes and platelets account for most of the oxygen consumed by whole blood. ${ }^{3}$ Metabolic activities requiring oxygen persist in platelets, reticulocytes, and leucocytes after removal of blood from the vascular compartment. Normally these elements are present in such small amounts that the effect of this continued activity is negligible, However Chishiro and associates reported detectable arterial blood gas tension effects from both high and low platelet counts. ${ }^{3}$ With normal numbers of cells the oxygen consumption of each is approximately equal because, even though metabolic respiration of an average leucocyte is approximately 45 times that of a platelet, platelets are about 50 times more numerous 
than leucocytes. ${ }^{4}$ When white blood counts exceed approximately $50000 / \mathrm{mm}^{3}$ their metabolism will almost inevitably produce a noticeable decrease in the plasma oxygen tension. Furthermore, the type of blood component increased will affect the rate of oxygen consumption. ${ }^{25}$ It has been postulated that leukaemic cells have a higher metabolic rate than normal cells and, of these, the blast forms have the highest rate of all. ${ }^{6}$ Hess and associates reported that the $\mathrm{PO}_{2}$ of blood stored in a syringe and kept at room temperature falls at a faster rate in patients with higher numbers of circulating leucocytes or platelets than in control subjects, and that the fall is sufficiently significant to give an incorrect diagnosis of hypoxaemia. $^{2}$

In the interval between taking an arterial blood sample and analysing it, the sample should be placed in ice. Once in the blood gas analyser the temperature rapidly increases to approximately $37^{\circ} \mathrm{C}$. If these steps are prolonged or the sample is not iced the $\mathrm{PO}_{2}$ will fall. In the presence of extreme leucocytosis this fall is accelerated and can lead to an incorrect diagnosis of hypoxaemia.

Pulse oximetry measures haemoglobin saturation directly and is unaffected by the plasma oxygen tension. It is the simplest method of confirming leucocyte larceny and determining a patient's true oxygenation status. ${ }^{6}$ It is unlikely that increased levels of white blood cells would produce a falsely increased oxygen saturation with this technique since formed blood elements are not generally considered a source of error for oximetric oxyhaemoglobin determination.

1 Fox M, Brody J, Weintraub W. Leukocyte larceny: a cause of spurious hypoxemia. Am $\mathcal{F}$ Med 1979;67:742-6.

2 Hess CE, Nichols AB, Hunt WB, Suratt PM. Pseudohypoxemia secondary to leukemia and thrombocytosis. $N$ Engl f Med 1979;301:361-3.

3 Chishiro T, Suzuki K, Matsuo N. The platelet count in false hyperoxemia and hypoxemia (abstract). Am $\mathcal{f}$ Emerg Med hyperoxemia

4 Chishiro T, Suzuki K, Matsuo N. Metabolism of the circulating leukocyte. Physiol Rev 1965;45:674-720.

5 Hedeskov LJ, Esmann V. Respiration and glycolysis of normal human lymphocytes. Blood 1966;28:163-74.

6 Loke J, Duffy T. Normal arterial oxygen saturation with the ear oximeter in patients with leukemia and leukocytosis. Cancer 1984;53:767-9.

\section{Malignant chondroid syringoma presenting as multiple pulmonary nodules}

\author{
John L Kiely, Barbara Dunne, \\ Mary McCabe, Walter T McNicholas
}

\begin{abstract}
Malignant chondroid syringoma, a very rare tumour, presenting with multiple pulmonary metastases in a 50 year old woman is described. Initial diagnostic confusion with pulmonary hamartoma occurred due to histopathological similarities. However, re-examination of a skin biopsy specimen taken 17 years previously from a hand lesion yielded the necessary information to identify the pulmonary lesions definitively as metastases from the original skin lesion. The features of this very rare indolent tumour are described.

(Thorax 1997;52:395-396)
\end{abstract}

Keywords: malignant chondroid syringoma, pulmonary metastases, hamartoma, skin lesion.

\section{Case report}

A 50 year old woman was incidentally discovered to have multiple rounded opacities in both lung fields, on a routine chest radiograph performed during the assessment of neck pain (fig 1), which ranged from 0.25 to $2.0 \mathrm{~cm}$ in diameter on a computed tomographic scan of the thorax. She denied any respiratory symptoms such as cough, dyspnoea, or chest pain, and had no clinical, laboratory, or radiological features of occult malignancy on subsequent detailed assessment. Histological examination of a transthoracoscopic lung biopsy specimen indicated a diagnosis of multiple chondroid hamartomas.

Over the next 18 months the lesions slowly increased in size and full re-evaluation was undertaken. An enquiry regarding a small scar on her left hand revealed that a slowly growing mass had been excised 17 years previously from her left thenar eminence in another hospital. The patient had not disclosed this information on her initial examination as she felt it was irrelevant. The original pathological slides were subsequently retrieved from that hospital and compared with the tissue from the transthoracoscopic lung biopsy specimen. The diagnosis was revised accordingly to that of multiple pulmonary metastases from a malignant chondroid syringoma on the basis of histological and immunocytochemical staining and the marked histopathological similarity of the

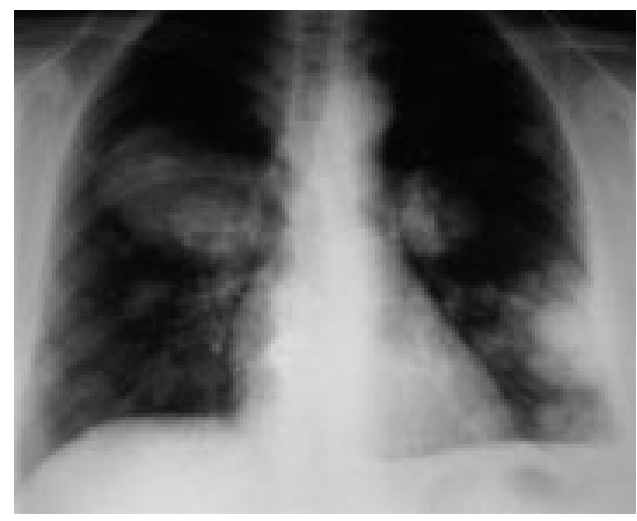

Figure 1 Chest radiograph showing multiple pulmonary metastases of varying size from a malignant chondroid syringoma. 


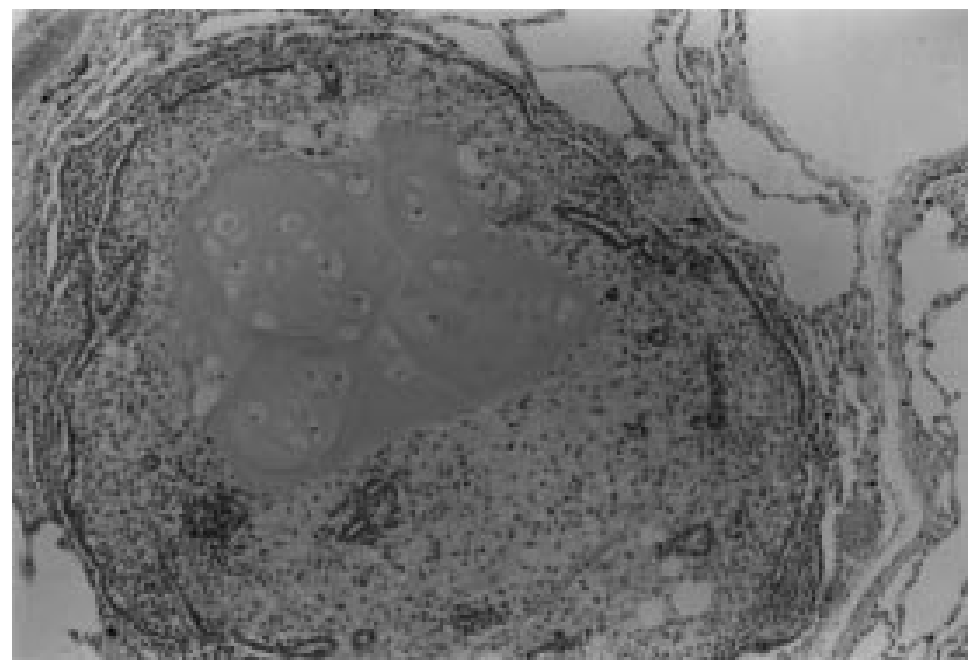

Figure 2 Photomicrograph of a pulmonary metastasis from a transthoracoscopic lung biopsy specimen showing well defined chondroid areas with lacunae and areas of myxoid stroma with epithelial ducts surrounded by lung parenchyma. Stain: haematoxylin and eosin; original magnification $\times 100$

two tumours. The patient has since developed slowly increasing dyspnoea on exertion with a gradual increase in tumour size but otherwise remains well.

\section{HISTOPATHOLOGY}

Histological examination of the biopsy material revealed the typical microscopic features of this type of tumour - namely, nests of cuboidal or polygonal cells, tubulo-alveolar structures with two or more rows of cuboidal cells, and a matrix of varying appearance, usually chondroid or myxoid (fig 2). ${ }^{1}$ The inner layer of cells lining the duct-like structures appeared to be epithelial in origin, but the outer layer and the cells surrounding in the stroma were considered to be myoepithelial in origin, with a polyhedral or spindle shape, and may have been responsible for generation of the mesenchymal chondromyxoid stroma. ${ }^{2-4}$

In keeping with reports of benign forms of this type of tumour, immunohistochemical studies $^{35}$ in this case demonstrated the inner (epithelial) cell layer to stain positively for cytokeratin, epithelial membrane antigen, and carcinoembryonic antigen. The outer (myoepithelial) cells stained positively for S-100 protein and muscle-specific actin.

\section{Discussion}

Benign chondroid syringoma, previously referred to as "the mixed tumour of the skin", is a neoplasm with microscopic features that indicate both epithelial and mesenchymal origin which usually spare the body extremities. The name "chondroid syringoma" was proposed because of the invariable presence of sweat gland elements and the prominent component of cartilage-like material in most tumours. ${ }^{26}$ Clinically these tumours can be indistinguishable from many other skin lesions and may present as a firm discrete subcutaneous nodule which is usually mobile underneath the overlying skin. Most benign syringomas are removed for cosmetic or diagnostic purposes, but pain or discomfort may be more frequent with the malignant lesion which may have a more aggressive local appearance. ${ }^{7}$

Malignant chondroid syringoma is the least common variety of sweat gland carcinomas and case reports have been relatively few. ${ }^{7-10}$ The histopathological features of this malignant tumour may be very similar to the benign type but, unlike their benign counterpart, they seem to have a predilection for the extremities and for the female sex. This seems to favour the theory that these tumours do not arise from pre-existing benign tumours at the same site. Most previously reported malignant chondroid syringomas were diagnosed by examination of metastases, which usually involved lymph nodes, lung, or both. ${ }^{8}$ Local recurrence and bony metastases are less common. ${ }^{7}$ The longest reported time from initial excision to discovery of metastases is 13 years; this patient continued to remain apparently well at 17 years following the initial diagnosis. ${ }^{8}$ Treatment options with chemotherapy or radiotherapy do not appear to have a favourable effect, ${ }^{79}$ but data are scarce on the non-surgical treatment of this rare type of tumour.

The difficulty in establishing an initial diagnosis in this case is not surprising when one considers the rarity and slow growth of the tumour. The lack of features typical of malignancy, the histopathological similarity of the biopsied lesion to a pulmonary hamartoma with a high degree of tissue differentiation, and the initially silent clinical picture contributed to this difficulty. In addition, the patient's poor recollection of the initial (seemingly trivial) excised lesion 17 years previously and the current lack of a regional tumour registry were also factors in the delayed diagnosis.

This case re-emphasises the value and importance of taking a repeat full history and examination, as well as the necessity of obtaining previous biopsy specimens for re-examination, particularly where an atypical tumour or unusual tumour behaviour is suspected.

Dr J L Kiely is supported by a fellowship grant from the Irish Health Research Board.

1 Hirsch P, Helwig EB. Chondroid syringoma: mixed tumor of the skin, salivary type. Arch Dermatol 1961;84:835-47. 2 Varela-Duran J, Diaz-Flores L, Varela-Nunez R. Ultrastructure of chondroid syringoma: role of the myoepithelial cell in the development of the mixed tumor of the skin and soft tissues. Cancer 1979;44:148-56.

3 Iglesias FD, Forcelledo FF, Sanchez TS, Garcia LF, Zapatero AH. Chondroid syringoma: a histological and (15 cases. Histopathology 1990;17:311-7.

4 Hernandez FJ. Mixed tumors of the skin of the salivary gland type: a light and electron microscopic study. F Invest .

5 Argenyi ZB, Balogh K, Goeken JA. Immunohistochemical characterization of chondroid syringomas. Am f Clin Pathol 1988;90:662-9.

6 Stout AP, Gorman JG. Mixed tumors of the skin of the salivary gland type. Cancer 1959;12:537-43.

7 Gupta S, Kumar A, Padmanabhan A, Khanna S. Malignan chondroid syringoma: a clinicopathologic study and a collective review. F Surg Oncol 1982;20:139-44.

8 Harrist TJ, Aretz TH, Mihm MC, Evans GW, Rodriquez FL. Cutaneous malignant mixed tumor. Arch Dermatol 1981;117:719-24.

9 Shvili D, Rothem A. Fulminant metastasizing chondroid syringoma of the skin. Am f Dermatopathol 1986;8:321-5.

10 Watson JAS, Walker MM, Smith NP, Hunt DM. Malignan chondroid syringoma - a rare cause of secondary bone tumour. Clin Exp Dermatol 1991;16:306-7. 